\title{
Antenatal and Postnatal Assessment of Neurobehavior: Which One should be used?
}

\author{
Milan Stanojevic
}

\begin{abstract}
It is obvious that this environment is quite different from one man is experiencing after birth, but, although different, intrauterine environment is ideal at that stage of human development. There is a question of the environmental discontinuity between intrauterine conditions characterized by existence of microgravity (baby astronaut hypothesis), and extrauterine life with gravity as developmental condition sine qua non. The human brain is one of the organs which is very sensitive to environmental changes affecting its growth and development. The brain of very tiny prematurely born babies is unable to follow the genetically determined growth pattern in extrauterine environment, even when postnatal nutrition and nurturing of the babies according to our best knowledge are appropriate. Is this fact of any significance to make distinction between normal and abnormal neurodevelopment pre- and postnatally is still unclear?

Kurjak antenatal neurodevelopmental test (KANET) using four-dimensional ultrasound (4D US) has been introduced using ten parameters and after attempt of standardization only eight parameters remained for neurodevelopmental assessment of low- and high-risk fetuses. We believe that at present level of knowledge, KANET test could be considered as a good test for the detection of fetuses with high neurological risk, without the possibility to define reliable long-term neurodevelopmental outcome. This is also hardly possible based on postnatal neurological assessment with 27 different postnatal tests. They were primarily neurobehavioral or neuromotor assessments that were suitable for use with preterm infants, and were discriminative, predictive or evaluative.
\end{abstract}

There was a high willingness of clinician to find postnatal neurodevelopmental test which could be predictive for shortterm and long-term outcome of low and high-risk infants.

Although, there are many tests available for prenatal and postnatal assessment of neurodevelopment, none of them is reliable in the prediction of neurodevelopmental outcome in low-risk population, while many could be used with fairly acceptable predictivity in high-risk population. Although, many studies have been conducted in order to solve this problem, still there is a space for improvement. In postnatal period we are dealing with infant in front of the clinician with direct observation, while pretnatally we are dealing with quite different environment and less mature brain.

\section{Associate Professor}

Department of Obstetrics and Gynecology, Medical School University of Zagreb, DIU Libertas International University, Sveti Duh Clinical Hospital, Zagreb, Croatia

Corresponding Author: Milan Stanojevic, Associate Professor Department of Obstetrics and Gynecology, Medical School University of Zagreb, Sveti Duh Clinical Hospital, Sveti Duh 64 10000 Zagreb, Croatia, Phone: 0038513712316 , e-mail: milan. stanojevic@optinet.hr
Keywords: Neurodevelopment, Prenatal assessment, Postnatal assessment, Four-dimensional ultrasound, Kurjak antenatal neurodevelopmental test, Gravity.

How to cite this article: Stanojevic M. Antenatal and Postnatal Assessment of Neurobehavior: Which One should be used? Donald School J Ultrasound Obstet Gynecol 2015;9(1):67-74.

Source of support: Nil

Conflict of interest: None

\section{INTRODUCTION}

The development of ultrasound and other imaging techniques enabled better insight into the gravid uterus and its content, ${ }^{1}$ nevertheless still intrauterine environment is mysterious and unexplored. It is obvious that this environment is quite different from one man is experiencing after birth, but, although different, intrauterine environment is ideal at that stage of human development. There is a question of the environmental discontinuity between intrauterine conditions characterized by existence of microgravity and extrauterine life with gravity as developmental condition sine qua non. ${ }^{2,3}$

Growth velocity of weight, height and different organs during human development is crucial and should be preserved in order to enable normal outcome. ${ }^{4}$ Fetal growth velocity is quite different than infant growth velocity. ${ }^{4}$ The human brain is one of the organs which is very sensitive to environmental changes affecting its growth and development. The brain of very tiny prematurely born babies is unable to follow the growth pattern designated genetically in extrauterine environment even when postnatal nutrition and nurturing of the babies according to our best knowledge are appropriate. ${ }^{4,5}$ Is this fact of any significance to make distinction between normal and abnormal neurodevelopment pre- and postnatally is still unclear? There is a strong willingness of healthcare professionals to find out if there is a correlation between impaired developmental, structural, and processes at the cellular and molecular level with functional impairment of the central nervous system. Still, there is very little progress on that very intriguing issue. There is an attempt to use so called four-dimensional ultrasound (4D US) in order to make a functional prenatal screening test for detection of neurological impairment in utero. On the other hand, there are 27 different test for postnatal assessment 
of which only eight are enabling acceptable assessment of neuromotor and neurobehavioral assessment in order to predict short- or long-term outcome of high-risk infants. ${ }^{4}$ The possibility for prediction of neurodevelopmental outcome of low-risk infants is still impossible or poor. ${ }^{5}$

The aim of the paper is to discuss if there is a possibility for prenatal and postnatal assessment of neuromotor and neurobehavioral development in order to make long-term prediction of developmental outcome on the grounds of present knowledge.

\section{Baby Astronaut Hypothesis}

It is obvious that intrauterine and extrauterine environments are different with significant repercussion on development of muscle fibers. ${ }^{6-9}$ According to the 'Baby Astronaut' or gravity, age, thermoregulation, and oxygenation (GATO) hypothesis which is trying to explain synergistic effect of environments different in gravity on motor system adaptation. 8 From the point of view of this hypothesis, development of human individual is characterized by three different strategies influencing adaptation of motor fibers to the environmental circumstances. 8,9

The first strategy is so called fetal microgravity (FM) strategy which is characterized by microgravity (gravity less than $1 \mathrm{G}<1$ ) in intrauterine environment, which is characterized by enhancing development of fast muscle fibers and phasic movements of the fetus to survive in heating, strongly hypoxic, although normal for fetus, immersion in amniotic fluid. ${ }^{8,9}$ The amount of amniotic fluid can influence development of fetal bones. In the first part of gestation, the human fetus develops under conditions similar to neutral floating and has an apparent weight which is approximately $5 \%$ of its actual weight. ${ }^{6-9}$ During the last trimester of gestation, the fetus overgrows the intrauterine cavity and its apparent body weight is 60 to $80 \%$ of its actual weight. Polyhydramnios can reduce the apparent weight of the fetus to 10 to $20 \%$ of its actual weight with the reduction of the mechanical stress on fetal bones, affecting their development and ossification.?

The second adaptation strategy is called gravitation/ Earth or GE strategy, characterized by postnatal environment and it could be compared with the astronaut landing to the Earth. 8,9 The environmental condition characterizing this strategy are lower, but still normal temperature, normoxia, $1 \mathrm{G}$ gravitation, healthy maturation of slow muscle fibers. ${ }^{8,9}$ The process of parturition can be considered as equivalent to cosmonaut's/astronaut's transition from microgravitation back to Earth gravitation ( $G=1$ ) during landing. ${ }^{8,9}$

During the third so called slow and Jupiter (the most massive planet and the only planet with $G>1$ in the solar system) (SJ) strategy the motor system undergoes a second profound remodeling in older people during healthy ageing that results in further domination of slow muscle fibers and slowing down motor unit activity, simulating the condition of hypergravitation $(G>1) .{ }^{8,9}$

GATO hypothesis implies that specific sensory conditions may substitute for each other owing to their synergistic action on the motor system. According to GATO hypothesis heating and hypoxia may be considered as 'promicrogravity' factors, while cold and hyperoxia - as 'progravity' ones. ${ }^{8,9}$

The development of antigravity muscular control is critical to normal motor development during the first year of life. After birth the newborn is exposed to the $1 G$ environment. Movement against gravity begins during the first month of life, and by 4 months of age increased flexion control balances the strong extensor muscle patterns. ${ }^{10}$ These movements enable the child to develop weight shifting, which in turn stimulates righting and equilibrium responses. ${ }^{10,11}$ The influence of the gravity on prenatal and postnatal development of motility could be considered as discontinuity from prenatal (low gravity) to postnatal life (high gravity) however it proves that different environmental conditions significantly influence behavior and development.

\section{Is There any Significance of Prenatal and Postnatal Growth Velocity on Neurodevelopment?}

It is obvious that there are differences in growth velocities of fetuses and infants. ${ }^{4}$ More than 60 years ago Tanner had described differences in prenatal growth velocities of the fetuses concluding that peak growth velocity of fetal height appears around 20 weeks of gestation while for weight it is around 30 weeks of gestation. ${ }^{12}$ Comparison of crown-heal length velocity pre- and postnatally is shown on the Graph $1 .^{12}$ There is a discontinuity between fetal and infant growth curves. There is considerable evidence that, beginning at 34 to 36 weeks, fetal growth slows down, owing to space constraints within the uterus. ${ }^{4,12} \mathrm{~A}$ hypothetical curve of weight gain velocities connecting a peak weight velocity point at 32 weeks, with a weight gain velocity point 8 weeks postpartum. ${ }^{4,12}$ Infants usually lose some weight immediately after birth which they then rapidly regain. On average, catch-up growth is greatest in those infants most delayed in utero. ${ }^{4}$ As a result, there is a significant negative correlation between birth weight and length gain in the early postnatal months. ${ }^{4}$

Head growth is very important representing growth of the brain. Tanner showed that head circumference, as shown on the Graph 2, was increasing from 15 to 25 weeks of gestation for around $11 \mathrm{~cm} .^{12}$ In the period of 11 postnatal weeks head circumference growth for boys increased for 5.5 and $5.0 \mathrm{~cm}$ for girls. ${ }^{13,14}$ Premature 


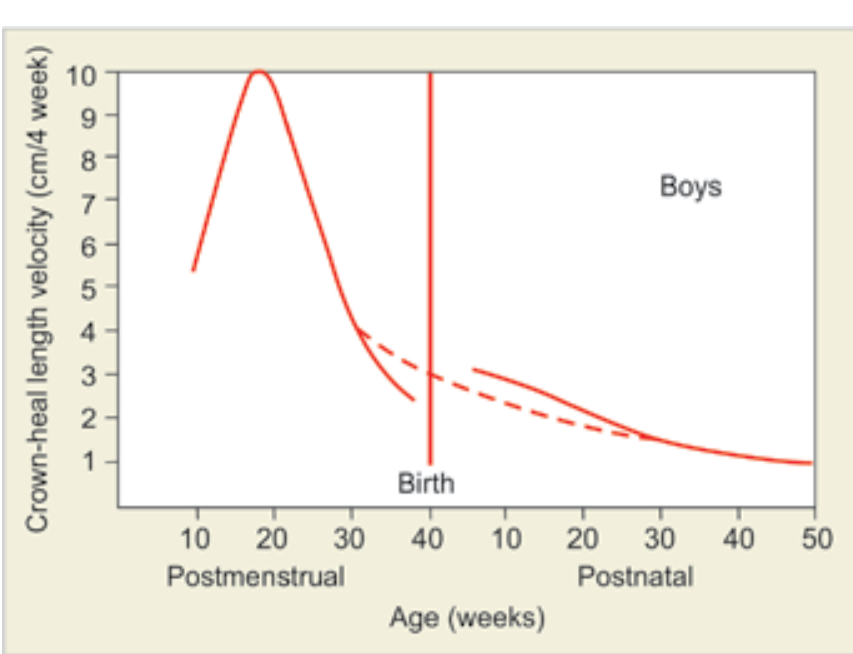

Graph 1: Crown-heel length velocity, $\mathrm{cm}$ per 4 weeks of gestational age ${ }^{12}$

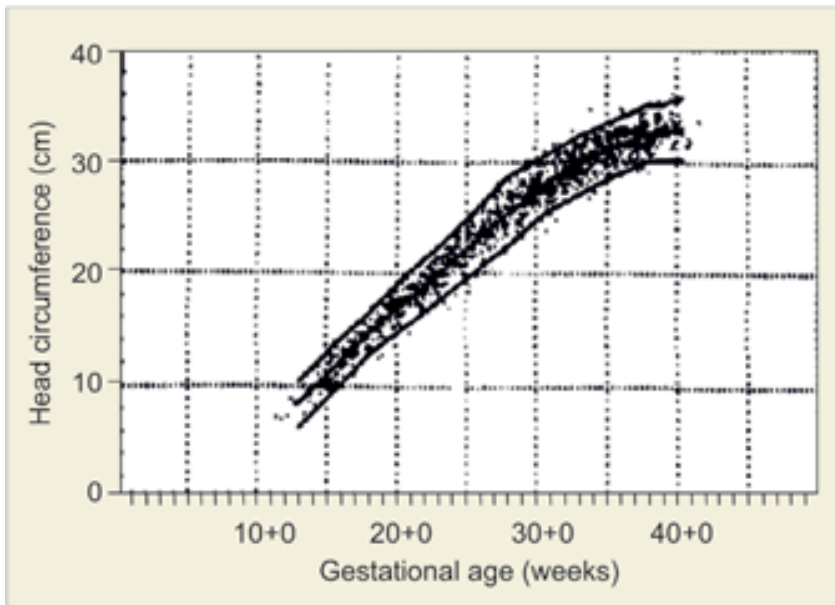

Graph 2: Distance curves of head circumference in $\mathrm{cm}$ for gestational age in weeks, with the 50 th centile and 2 standard deviations ${ }^{12}$

infants of gestational age 28 weeks and below are at risk for development of postnatal growth retardation which can continue to be present up to 11 years of age affecting body weight, height and head circumference. ${ }^{15}$ Almost $20 \%$ of 11-year-old children born between 23 and 25 weeks of gestation suffered from head circumference growth failure compared to only few percent of term born counterparts. ${ }^{15}$ This fact is important proving that preserving normal intrauterine growth velocity after premature birth between 23 and 25 weeks of gestation is extremely difficult and can cause many long lasting health problems like disturbed neurodevelopment.

\section{Prediction of Neurodevelopmental Outcome by Prenatal Neurologic Assessment}

More than 10 years four-dimensional (4D) ultrasound has been used in the assessment of fetal behavior, with numerous papers published by different authors and in many journals. ${ }^{16-64} 4 \mathrm{D}$ ultrasound for the assessment of fetal behavior used knowledge and experience which has been gained during study of fetal behavior by two dimensional (2D) ultrasound. ${ }^{23}$ After description of particular movements at the beginning, assessment of general movements (GMs) by $4 \mathrm{D}$ ultrasound has been introduced. ${ }^{16,18-22}$ Standards of the quantity of GMs throughout gestation has been published. ${ }^{24,25}$ From the prenatal study of GMs by 2D ultrasound and by postnatal assessment of GMs, it was clear that quality of GMs is very important to be assessed, and so called 'gestalt perception' has been introduced to assessment of fetal GMs by $4 \mathrm{D}$ ultrasound. ${ }^{27-33}$ Than Kurjak antenatal neurodevelopmental test (KANET) has been introduced using ten parameters and after attempt of standardization only eight parameters remained for neurodevelopmental assessment of low- and high-risk fetuses. ${ }^{34,46}$ In the meantime many papers have been published on KANET test and fetal Doppler, in twin pregnancies, in intrauterine growth retardation, gestational diabetes, some fetal malformations like lysencephaly and anencephaly and many others. ${ }^{20,26,31,37,40,44,47,52,54,57-59,62-64}$ There have been many papers from different centers, and among them some were able to investigate many examinees with following two examples.

Prospective cohort study of 288 pregnant women were found eligible to be included in the study of fetal to neonatal behavior from high-risk pregnancies. ${ }^{37}$ Abnormal KANET scores have been found in 7 fetuses, and 25 fetuses were borderline, which gives all together 32 fetuses at neurological risk. ${ }^{37}$ Of 7 fetuses with abnormal KANET, postnatal neurological assessment by Amiel Tison's method (ATNAT) ${ }^{65}$ revealed 3 newborns (arthrogryposis, vermis aplasia and neonate of the mother with the previous child with cerebral palsy-CP) out of 7 fetuses to be abnormal, while 4 were considered normal (ventriculomegaly, preeclampsia, thrombophylia, oligohydramnios). ${ }^{65}$ Out of 25 borderline KANET fetuses there were 22 borderline newborns by ATNAT, while 3 were normal (ventriculomegaly, syndrome of intraamniotic infection, mother's thrombocytopenia).$^{65}$ Those who were abnormal prenatally and normal postnatally had following prenatal risk factors: ventriculomegaly, Dandy Walker syndrome, skeletal dysplasia, polyhydramnios, hydrocephaly, diabetes in pregnancy, nonimmune hydrops, syndrome of intra-amniotic infection, IUGR, trisomy 21, thrombocytopenia, thrombophylia, preeclampsia, achondroplasia, oligohydramnios. ${ }^{65}$ Out of 3 abnormal neonates after ATNAT assessment, 2 had definitely abnormal Prechtl's premature GMs ${ }^{66,67}$ (arthrogryposis and vermis aplasia), and additional 6 were considered abnormal (neonate of the mother with the previous child with CP, Dandy Walker syndrome, hydrocephaly, trisomy 21 , ventriculomegaly, nonimmune hydrops). ${ }^{65}$ Rest of 24 children had normal optimal or normal suboptimal GMs. ${ }^{65}$ 
In the study of 620 fetuses from singleton pregnancies KANET scores were studied between 26th and 38th week of gestation. ${ }^{40}$ Comparison of KANET scores in 100 low- and 520 high-risk singleton pregnancies were expectedly statistically significant. ${ }^{40}$ The largest incidence of fetuses with abnormal KANET was in the group of fetuses who had siblings with cerebral palsy. ${ }^{40}$ The largest incidence of the borderline KANET has been found in the group of fetuses whose mothers had fever during pregnancy. ${ }^{40}$ The following parameters of KANET test significantly differed between the fetuses from low- and high-risk pregnancies: overlapping cranial sutures, head circumference, isolated eye blinking, facial expressions, mouth movements, isolated hand movements, isolated leg movements, hand to face movement, finger movements, and general movements. ${ }^{40}$

Kurjak et al conducted a study by $4 \mathrm{D}$ ultrasound and confirmed earlier findings made by 2D ultrasonography, that there is behavioral pattern continuity from prenatal to postnatal life. ${ }^{17,68}$ It has been speculated that intrauterine detection of encephalopathy would improve the outcome. Although, many fetal behavioral studies have been conducted, it is still questionable whether the assessment of continuity from fetal to neonatal behavior could improve ability for early detection of disturbed neurodevelopment. Early detection could possibly rise an opportunity to intervene and even prevent the expected damage. ${ }^{69}$ Early intervention programs for preterm infants have a positive influence on cognitive outcomes in the short to medium term..$^{69,70}$

It would be wise to consider long run prognosis, for each specific type of fetal brain damage and make appropriate decisions for management. ${ }^{69}$ However, this did not happen yet. We believe that KANET test on the ground of published studies could be considered as a good test for the detection of fetuses with high neurological risk, without the possibility to define reliable long-term neurodevelopmental outcome. KANET test applied alone in the low-risk fetal population either normal or abnormal, can not be used for the prediction of neurodevelopmental outcome due to different intrauterine and extrauterine environment and plasticity of the brain. New well designed long lasting double blind studies are needed in order to prove clinical prognostic value of KANET test or any other method of prenatal neurological assessment. It would be interesting to see whether postnatal assessment of low- and high-risk neonates and infants could add some new prognostic possibilities for their long-term neurodevelopmental outcome.

\section{Prediction of Neurodevelopmental Outcome by Postnatal Neurologic Assessment}

Long- and short-term neurodevelopmental outcome of high- and low-risk infants has been in the focus of interest of investigators and clinicians for many years. If neurodevelopment was very much disturbed there was a possibility to predict it in most of the infants, although in some individuals with severely affected neurodevelopment in infancy, at the age of small child or young adolescent, clinicians were surprised with encouraging outcome due to brain plasticity. This was the reason why definition cerebral palsy $(\mathrm{CP})$ changed many times in the last several decades. When trying to predict the future of high-risk babies in terms of individual neurodevelopment, than one should always bear in mind that it is only statistical category without possibility to predict neurodevelopment on individual basis.

\section{General Movements (GMs)}

In one systematic review of the literature, the authors aimed to systematically assess available data in order to determine the evidence of general movements in early infancy to predict the neurodevelopmental outcome in 12- and 24-month-old infants. ${ }^{71}$ Fifteen of the 17 studies found a high relationship (sensitivity $>$ or $=92 \%$; specificity $>$ or $=82 \%$; $p<0.01$ ) between the quality of GMs at 8 to 20 weeks post-term (fidgety movements' period) and the infants' neurodevelopmental outcome. ${ }^{71}$ They concluded that obtained results indicate that the qualitative assessment of GMs, especially during the fidgety movements' period, can be used as a prognostic tool to identify infants with neurodevelopmental disabilities. ${ }^{71}$ On the other hand a single preterm GM assessment is only fairly to moderately associated with the 14-month motor development and could not be used for prediction of neurodevelopmental outcome. ${ }^{72}$ Contrary, in the late preterm infants the significant correlation has been found between prediction of $\mathrm{CP}$ and impaired fidgety $\mathrm{GMs}{ }^{73}$ Impaired fidgety GMs could be used for detection of highrisk late preterm infants who need early intervention. ${ }^{73}$

In another systematic review with 39 studies included, separated according to the age at follow-up: 12 to 23 months, 2 to 3,4 to 11 , and 12 to 18 years, authors found that outcome measures differed greatly among the studies. ${ }^{74}$ Values for sensitivity, specificity, positive predictive value, and negative predictive value varied among studies. ${ }^{74}$ The overall trend indicated that the presence of abnormalities in the quality of fidgety movements at 12 weeks adjusted age is more predictive of adverse outcomes than abnormal writhing movements. ${ }^{74}$ Authors concluded that GMs assessment demonstrates potential as a cost-effective, nonintrusive means of infant assessment however current studies include important sources of bias, which prompted authors to advocate for future methodologically more rigorous studies with functional outcomes. $^{74}$ 
It was always interesting how to make prediction on neurodevelopment in term and preterm infants by assessment of movements and posture. In the recent study made by Yang et al aimed to determine whether an association between the early motor repertoire and the Gross Motor Function Classification System (GMFCS) also holds true for children born at term. ${ }^{75}$ They included 79 infants ( 60 boys and 19 girls; 47 infants born at term; video recorded for the assessment of movements and posture at age 9 to 20 weeks post-term age) who developed $\mathrm{CP} .^{75}$ The GMFCS was applied in examinees at age 2 to 5 years. ${ }^{75}$ Motor optimality at age 3 to 5 months showed a significant correlation with functional mobility and activity limitation as classified on the GMFCS at age 2 to 5 years in both children born at term and born preterm. ${ }^{75}$ Infants born preterm were more likely to show normal movement patterns than infants born at term. A normal posture and abnormal, jerky (yet not monotonous) movements resulted in better levels of function and mobility. With the exception of one, none of the infants showed fidgety movements. ${ }^{75}$ A cramped-synchronized movements, repetitive opening and closing of the mouth, and abnormal finger postures characterized children who would show a poor self-mobility later. ${ }^{75}$ At the end the authors cautiously concluded that assessing the quality of motor performance at post-term age of 9 to 20 weeks (irrespective of the gestational age) improves ability to predict later functional limitations in children with $\mathrm{CP}^{75}$

In the study of 53 preterm infants born at gestational age of less than 27 weeks, authors investigated how GMs assessment and magnetic resonance imaging (MRI) could predict later $\mathrm{CP} .{ }^{76}$ Authors concluded that the presence of definitely abnormal GMs was predictive of $\mathrm{CP}$ with significantly enhanced prediction when the GMs assessment was combined with findings from MRI obtained at term equivalent age. ${ }^{76}$

There were studies which were assessing disturbances of swallowing and uncoordinated sucking in high-risk preterm infants for the prediction of neurodevelopmental outcome. In one study and uncoordinated sucking patterns were associated with abnormal GMs in highrisk preterm infants. ${ }^{77}$ Uncoordinated sucking patterns were associated with abnormal fidgety movements, indicating that uncoordinated sucking, swallowing, and breathing may represent neurologic dysfunction. ${ }^{77}$ However in the systematic review of the literature authors concluded that there is currently insufficient evidence to clearly determine the relation between early sucking and swallowing problems and neonatal brain injury. ${ }^{77}$ Although, early sucking and swallowing problems may be related to later neurodevelopmental outcomes, further research is required to delineate their value in predicting later motor outcomes and to establish reliable measures of early sucking and swallowing function. ${ }^{78}$

There are many tests available to assess neurodevelopment of preterm and high-risk newborns, but still standardized and generally acceptable tests are missing. In a systemic review of 27 available tests at the corrected age of 4 months, authors investigated the clinimetric properties of longitudinal neonatal neurobehavioral and neuromotor assessments for preterm infants. ${ }^{5}$ Out of 27 available tests the following eight tests fulfilled inclusion criteria: assessment of preterm infants' behavior (APIB), neonatal intensive care unit network neurobehavioral scale (NNNS), test of infant motor performance (TIMP), Prechtl's assessment of general movements (GMs), neurobehavioral assessment of the preterm infant (NAPI), Dubowitz neurological assessment of the preterm and full-term infant (Dubowitz), Neuromotor behavioral assessment (NMBA), and the Brazelton neonatal behavioral assessment scale (NBAS). ${ }^{5}$ The primary purpose included prediction (TIMP, GMs, Dubowitz), discrimination (all assessments), and evaluation of change (TIMP, NAPI). Measures of assessment were included in the study if they were (1) primarily neurobehavioral or neuromotor assessments that were suitable for use with preterm infants ( $<37$ weeks gestation) up to 4 months corrected age and were discriminative, predictive, or evaluative; (2) standardized procedures designed for serial/longitudinal use; or (3) criterion or norm referenced. ${ }^{5}$ All of the measures included in the review demonstrated adequate content and construct validity. Concurrent validity was reported for APIB, NNNS, Dubowitz and GMs. Predictive validity was high for GMs with studies reporting up to $100 \%$ sensitivity for predicting cerebral palsy at the age of 12 to 24 months. ${ }^{5}$ Interrater reliability was strong for the TIMP, GMs, and moderate for the NAPI. ${ }^{5}$ Clinical utility was variable for ease of scoring, interpretability, cost and access. In the absence of a criterion standard for neonatal neuromotor assessments, the NNNS and APIB have strong psychometric qualities with better utility for research. ${ }^{5}$ Similarly, the GMs, TIMP and NAPI have strong psychometric qualities but better utility for clinical settings. ${ }^{5}$ The GMs has best prediction of future outcome and the TIMP has best evaluative validity. ${ }^{5}$

A systematic review of neurodevelopmental tests to predict $\mathrm{CP}$ in young children has been recently published. ${ }^{79}$ Systematic review evaluated the accuracy of predictive assessments and investigations used to assist in the diagnosis of $\mathrm{CP}$ in children up to 5 years of age. ${ }^{79}$ Nineteen out of 351 studies met the full inclusion criteria, including studies of GMs assessment, cranial ultrasound, brain MRI and neurological examination. ${ }^{79}$ 
All studies assessed high-risk populations including preterm (gestational range 23-41 weeks) and low-birth weight infants (500-4350 gm). ${ }^{79}$ Summary estimates of sensitivity and specificity of GMs assessment were 98\% (95\% confidence interval [CI] 74-100\%) and 91\% (95\% CI $83-93 \%)$ respectively; of cranial ultrasound $74 \%$ (95\% CI $63-83 \%)$ and $92 \%$ (95\% CI 81-96\%) respectively; and of neurological examination 88\% (95\% CI 55-97\%) and 87\% (95\% CI 57-97\%) respectively. ${ }^{79}$ MRI performed at term corrected age (in preterm infants) appeared to be a strong predictor of $\mathrm{CP}$, with sensitivity ranging in individual studies from 86 to $100 \%$ and specificity ranging from 89 to $97 \% .{ }^{79}$ This review found that the assessment with the best evidence and strength for predictive accuracy is the GMs assessment. MRI has a good predictive value when performed at term-corrected age. ${ }^{79}$ Cranial ultrasound is as specific as MRI and has the advantage of being readily available at the bedside. Studies to date have focused on high-risk infants. ${ }^{79}$ The accuracy of these tests in low-risk infants remains unclear and requires further research. ${ }^{79}$

\section{CONCLUSION}

There was a high willingness of clinician to find postnatal neurodevelopmental test which could be predictive for short-term and long-term outcome of low and high-risk infants. Although, there are many tests available, none of them is reliable in the prediction of neurodevelopmental outcome in low-risk population, while many could be used with fairly acceptable predictivity in high-risk population. Although, many studies have been conducted in order to solve this problem, still there is a space for improvement. In postnatal period we are dealing with infant in front of the clinician with direct observation, while prenatally we are dealing with quite different environment and less mature brain. By observing fetus during its development lasting 280 days during which ontogenesis is recapitulating phylogenesis there is not much time to make prediction of postnatal neurodevelopmental outcome. Although, postnatally we have much more different methods to make prediction of neurodevelopmental outcome at the age of 1095 days or later, this is still not easy task to fulfill especially in low-risk population.

\section{REFERENCES}

1. Kurjak A. Ultrasound scanning - Prof. Ian Donald (1910-1987). Eur J Obstet Gynecol Reprod Biol 2000;90:187-189.

2. Stanojevic M, Kurjak A, Salihagić-Kadić A, Vasilj O, Miskovic B, Shaddad AN, Ahmed B, Tomasović S. Neurobehavioral continuity from fetus to neonate. J Perinat Med 2011;39:171-177.

3. Stanojevic M, Zaputovic S, Pavicic Bosnjak A. Continuity between fetal and neonatal neurobehavior. Seminars in Fetal and Neonatal Med 2012;17:324-329.
4. Falkner F, Holzgreve W, Schloo RH. Prenatal influences on postnatal growth: overview and pointers for needed research.http://archive.unu.edu/unupress/food2/UID06E/ UID06E06.HTM

5. Noble Y, Boyd R. Neonatal assessments for the preterm infant up to 4 months corrected age: a systematic review. Dev Med Child Neurol 2012;54(2):129-139.

6. Sekulić SR, Lukac DD, Naumović NM. The fetus cannot exercise like an astronaut: gravity loading is necessary for the physiological development during second half of pregnancy. Med Hypotheses 2005;64(2):221-228.

7. Sekulić SR, Ilić D, Novakov-Mikić A. Polyhydramnios and bone development: an unexplored relationship. Med Hypotheses 2010;75(3):312-314.

8. Meigal A. Interplanetary space flight compared with fetal/neonatal motor strategy: theoretical and practical implications. Pathophysiol 2012;19(4):269-276.

9. Meigal AY. Synergistic action of gravity and temperature on the motor system within the lifespan: a 'Baby Astronaut' hypothesis. Med Hypotheses 2013;80(3):275-283.

10. Assaiante C, Mallau S, Viel S, Jover M, Schmitz C. Development of postural control in healthy children: a functional approach. Neural Plast 2005;12:109-118.

11. Sellers JS. Relationship between antigravity control and postural control in young children. Phys Ther 1988;68:486-490.

12. Tanner JM. Foetus into man. Cambridge, MS: Harvard University Press, 1950.

13. World Health Organization, United Nations Children's Fund. WHO child growth standards and the identification of severe acute malnutrition in infants and children. A Joint Statement. World Health Organization, Geneva, 2009.

14. World Health Organization. Child growth standards. http:// www.who.int/childgrowth/en/

15. Farooqi A, Hägglöf B, Sedin G, Gothefors L, Serenius F. Growth in 10- to 12-year-old children born at 23 to 25 weeks' gestation in the 1990s: a Swedish national prospective follow-up study. Pediatrics 2006;118;e1452-e1465.

16. Kurjak A, Azumendi G, Vecek N, Kupesic S, Solak M, Varga D, Chervenak F. Fetal hand movements and facial expression in normal pregnancy studied by four-dimensional sonography. J Perinat Med 2003;31(6):496-508.

17. Kurjak A(1), Stanojevic M, Andonotopo W, Salihagic-Kadic A, Carrera JM, Azumendi G. Behavioral pattern continuity from prenatal to postnatal life-a study by four-dimensional (4D) ultrasonography. J Perinat Med 2004;32(4):346-353.

18. Kurjak A, Stanojevic M, Azumendi G, Carrera JM. The potential of four-dimensional $(4 \mathrm{D})$ ultrasonography in the assessment of fetal awareness. J Perinat Med 2005;33(1):46-53.

19. Hata T, Kanenishi K, Akiyama M, Tanaka H, Kimura K. Realtime 3-D sonographic observation of fetal facial expression. J Obstet Gynaecol Res 2005;31(4):337-340.

20. Andonotopo W, Kurjak A, Kosuta MI. Behavior of an anencephalic fetus studied by $4 \mathrm{D}$ sonography. J Matern Fetal Neonatal Med 2005;17(2):165-168.

21. Kurjak A, Stanojevic M, Andonotopo W, Scazzocchio-Duenas E, Azumendi G, Carrera JM. Fetal behavior assessed in all three trimesters of normal pregnancy by four-dimensional ultrasonography. Croat Med J 2005;46(5):772-780.

22. Kurjak A, Carrera J, Medic M, Azumendi G, Andonotopo W, Stanojevic M. The antenatal development of fetal behavioral patterns assessed by four-dimensional sonography. J Matern Fetal Neonatal Med 2005;17(6):401-416. 
23. Andonotopo W, Medic M, Salihagic-Kadic A, Milenkovic D, Maiz N, Scazzocchio E. The assessment of fetal behavior in early pregnancy: comparison between $2 \mathrm{D}$ and $4 \mathrm{D}$ sonographic scanning. J Perinat Med 2005;33(5):406-414.

24. Kurjak A, Andonotopo W, Hafner T, Salihagic Kadic A, Stanojevic M, Azumendi G, Ahmed B, Carrera JM, Troyano JM. Normal standards for fetal neurobehavioral developments-longitudinal quantification by four-dimensional sonography. J Perinat Med 2006;34(1):56-65.

25. Yigiter AB, Kavak ZN. Normal standards of fetal behavior assessed by four-dimensional sonography. Matern Fetal Neonatal Med 2006;19(11):707-721.

26. Andonotopo W, Kurjak A. The assessment of fetal behavior of growth restricted fetuses by $4 \mathrm{D}$ sonography. J Perinat Med 2006;34(6):471-478

27. de Vries JI, Fong BF. Normal fetal motility: an overview. Ultrasound Obstet Gynecol 2006;27(6):701-711.

28. Kurjak A, Stanojevic M, Salihagic-Kadic A, Azumendi G, Spalldi L, Miskovic B. Fetal neurology-lesson learned and future challenges. Donald School J Ultrasound Obstet Gynecol 2007;1(3):26-36.

29. Kurjak A, Stanojevic M, Marton I, Herman M, AzumendiG. An attempt to discover antenatal etiological factors for cerebral palsy: what does 3D and 4D ultrasonography add? Donald School J Ultrasound Obstet Gynecol 2007;1(4):29-39.

30. Salihagic Kadic A, Predojevic M, Kurjak A. Advances in fetal neurophysiology. Donald School J Ultrasound Obstet Gynecol 2008;2(3):19-34.

31. Kurjak A, Tikvica A, Miskovic B, Stanojevic M, Ahmed B, Vasilj O. Fetal behavior in high-risk pregnancies Assessed by two-dimensional (2D) and three-dimensional/fourdimensional (3D)/(4D) ultrasound: a review. Donald School J Ultrasound Obstet Gynecol 2008;2(3):35-47.

32. Stanojevic M, Kurjak A. Continuity between fetal and neonatal neurobehavior. Donald School J Ultrasound Obstet Gynecol 2008;2(3):64-75.

33. Azumendi G, Lausin I, Kurjak A, Pooh RK, Grant G. Ultrasonographic evaluation of fetal face by $3 \mathrm{D} / 4 \mathrm{D}$ sonography. Donald School J Ultrasound Obstet Gynecol 2008;2(4):45-57.

34. Kurjak A, Miskovic B, Stanojevic M, Amiel-Tison C, Ahmed B, Azumendi G, Vasilj O, Andonotopo W, Turudic T, SalihagicKadic A. New scoring system for fetal neurobehavior assessed by three- and four-dimensional sonography. J Perinat Med 2008;36(1):73-81.

35. Kurjak A, Tikvica A, Stanojevic M, Miskovic B, Ahmed B, Azumendi G, Di Renzo GC. The assessment of fetal neurobehavior by three-dimensional and four-dimensional ultrasound. J Matern Fetal Neonatal Med 2008;21(10):675-684.

36. Kim TH, Lee JJ, Chung SH, Lee HH, Lee KH, Choi KY, Lee SH. Efficacy of assessment in fetal behaviour by four dimensional ultrasonography. J Obstet Gynaecol 2010;30(5):439-443.

37. Kurjak A, Abo-Yaqoub S, Stanojevic M, Yigiter AB, VasiljO, Lebit D, Shaddad AN, Ahmed B, Kavak ZN, Miskovic B, et al. The potential of $4 \mathrm{D}$ sonography in the assessment of fetal neurobehavior-multicentric study in high-risk pregnancies. J Perinat Med 2010;38(1):77-82.

38. Kurjak A, Tikvica Luetic A, Stanojevic M, Talic A, Zalud I, Al-Noobi M, Perva S, Abushama M, Tomasovic S, Zaputovic $\mathrm{S}$, et al. Further experience in the clinical assessment of fetal neurobehavior. Donald School J Ultrasound Obstet Gynecol 2010;4(1):59-71.
39. Hata T, Kanenishi K, Tanaka H, Marumo G, Sasaki M. Fourdimensional ultrasound evaluation of fetal neurobehavioral development. Donald School J Ultrasound Obstet Gynecol 2010;4(3):233-248.

40. Talic A, Kurjak A, Ahmed B, Stanojevic M, Predojevic M, Kadic AS, Di Renzo GC. The potential of 4 D sonography in the assessment of fetal behavior in high-risk pregnancies. J Matern Fetal Neonatal Med 2011;24(7):948-954.

41. Lebit DF, Vladareanu PD. The Role of $4 \mathrm{D}$ Ultrasound in the assessment of fetal behaviour. Maedica (Buchar) 2011; 6(2): 120-127.

42. Tomasovic S, Predojevic M. 4D Ultrasound - medical devices for recent advances on the etiology of cerebral palsy. Acta Inform Med 2011;19(4):228-234.

43. Kurjak A, Predojevic M, Kadic AS. Fetal brain function: lessons learned and future challenges of $4 \mathrm{D}$ sonography. Donald School J Ultrasound Obstet Gynecol 2011;5(2):85-92.

44. Miskovic B, Vasilj O, Predojevic M. Fetal neurobehavior in normal and high-risk pregnancy. Donald School J Ultrasound Obstet Gynecol 2011;5(2):101-106.

45. Stanojevic M, Kurjak A. Continuity from fetal to neonatal behavior: lessons learned and future challenges. Donald School J Ultrasound Obstet Gynecol 2011;5(2):107-118.

46. Stanojevic M, Talic A, Miskovic B, Oliver V, Shaddad AN, Ahmed B, Kadic AS, Predojevic M, Vladareanu R, Lebit $D$, et al. An attempt to standardize Kurjak's antenatal neurodevelopmental test: Osaka consensus statement. Donald School J Ultrasound Obstet Gynecol 2011;5(4):317-329.

47. Talic A, Kurjak A, Stanojevic M, Honemeyer U, Badreldeen A, DiRenzo GC. The assessment of fetal brain function in fetuses with ventrikulomegaly: the role of the KANET test. J Matern Fetal Neonatal Med 2012;25(8):1267-1272.

48. Hata T, Hanaoka U, Tenkumo C, Sato M, Tanaka H, Ishimura $\mathrm{M}$. Three- and four-dimensional HDlive rendering images of normal and abnormal fetuses: pictorial essay. Arch Gynecol Obstet 2012;286(6):1431-1435.

49. Kurjak A, Stanojević M, Predojević M, Laušin I, SalihagićKadić A. Neurobehavior in fetal life. Semin Fetal Neonatal Med 2012;17(6):319-323.

50. Abo-Yaqoub S, Kurjak A, Mohammed AB, Shadad A, Abdel-Maaboud M. The role of 4-D ultrasonography in prenatal assessment of fetal neurobehaviour and prediction of neurological outcome. J Matern Fetal Neonatal Med 2012;25(3):231-236.

51. Hata T, Sato M, Kanenishi K, Hanaoka U, Tanaka H. 4D Sonography in assessment of fetal neurobehavior. Donald School J Ultrasound Obstet Gynecol 2012;6(2):121-131.

52. Vladareanu R, Lebit D, Constantinescu S. Ultrasound assessment of fetal neurobehavior in high-risk pregnancies. Donald School J Ultrasound Obstet Gynecol 2012;6(2):132-147.

53. Honemeyer $U, K u r j a k A$. Prenatal beginnings of temperament formation-myth or reality? Case study of a twin pregnancy. Donald School J Ultrasound Obstet Gynecol 2012;6(2):148-153.

54. Talic A, Kurjak A, Honemeyer U. Effect of maternal fever on fetal behavior assessed by KANET test. Donald School J Ultrasound Obstet Gynecol 2012;6(2):160-165.

55. Miskovic B, Predojevic M, Stanojevic M, Tikvica A, Kurjak A, Ivankovic D, Vasilj O. KANET Test: Experience of Zagreb Group. Donald School J Ultrasound Obstet Gynecol 2012;6(2):166-170. 
56. Antsaklis P, Antsaklis A. The assessment of fetal neurobehavior with four-dimensional ultrasound: the Kurjak antenatal neurodevelopmental test. Donald School J Ultrasound Obstet Gynecol 2012;6(4):362-375.

57. Kurjak A, Talic A, Honemeyer U, Stanojevic M, Zalud I. Comparison between antenatal neurodevelopmental test and fetal Doppler in the assessment of fetal well being. J Perinat Med 2013;41(1):107-114.

58. Athanasiadis AP, Mikos T, Tambakoudis GP, Theodoridis TD, Papastergiou M, Assimakopoulos E, Tarlatzis BC. Neurodevelopmental fetal assessment using KANET scoring system in low- and high-risk pregnancies. J Matern Fetal Neonatal Med 2013;26(4):363-368.

59. Honemeyer U, Talic A, Therwat A, Paulose L, Patidar R. The clinical value of KANET in studying fetal neurobehavior in normal and at-risk pregnancies. J Perinat Med 2013;41(2): 187-197.

60. Guimarães Filho HA, Araujo Júnior E, Mello Júnior CF, Nardozza LM, Moron AF. Assessment of fetal behavior using four-dimensional ultrasonography: current knowledge and perspectives. Rev Assoc Med Bras 2013;59(5):507-513.

61. Kanenishi K, Hanaoka U, Noguchi J, Marumo G, Hata T. 4D ultrasound evaluation of fetal facial expressions during the latter stages of the second trimester. Int J Gynaecol Obstet 2013;121(3):257-260.

62. Kurjak A, Talic A, Stanojevic M, Honemeyer U, Serra B, Prats P, Di Renzo GC. The study of fetal neurobehavior in twins in all three trimesters of pregnancy. J Matern Fetal Neonatal Med 2013;26(12):1186-1195.

63. Yigiter AB, Gonenc G, Isci H, Guducu N. The assessment of fetal behavior of a fetus with lissencephaly by $4 \mathrm{D}$ ultrasound. Donald School J Ultrasound Obstet Gynecol 2013;7(2):208-212.

64. Predojević M, Talić A, Stanojević M, Kurjak A, Salihagić Kadić A. Assessment of motoric and hemodynamic parameters in growth restricted fetuses - case study. J Matern Fetal Neonatal Med 2014;27(3):247-251.

65. Amiel-Tison C. Update of the Amiel-Tison neurological assessment for the term neonate or at 40 weeks corrected age. Pediatr Neurol 2002;27:196-212.

66. Einspieler C, Prechtl HFR, Bos AF, Ferrari F, Cioni G. Prechtl's method on the qualitative assessment of general movements in preterm, term and young infants. Mac Keith Press, Cambridge, 2004.

67. Hadders-Algra M. General movements: a window for early identification of children at high-risk for developmental disorders. J Pediatr 2004;145:S12-S18.
68. Stanojevic M, Perlman M, Andonotopo W, Kurjak A. From fetal to neonatal behavioral status. Ultrasound Rev Obstet Gynecol 2004;4:459-471.

69. Himmelmann K, Hagberg G, Beckung E, Hagberg B, Uvebrant $P$. The changing panorama of cerebral palsy in Sweden. IX. Prevalence and origin in the birth-year period 1995-1998. Acta Paediatr 2005;94:287-294.

70. Mutlu A, Livanelioğlu A, Korkmaz A.Assessment of 'general movements' in high-risk infants by Prechtl analysis during early intervention period in the first year of life. Turk J Pediatr 2010;52(6):630-637.

71. Burger M, Louw QA. The predictive validity of general movements-a systematic review. Eur J Paediatr Neurol 2009;13(5):408-420

72. Manacero SA, Marschik PB, Nunes ML, Einspieler C. Is it possible to predict the infant's neurodevelopmental outcome at 14 months of age by means of a single preterm assessment of General Movements?. Early Hum Dev 2012;88(1):39-43.

73. Brogna C, Romeo DM, Cervesi C, Scrofani L, Romeo MG, Mercuri E, Guzzetta A. Prognostic value of the qualitative assessments of general movements in late-preterm infants. Early Hum Dev 2013;89(12):1063-1066.

74. Darsaklis V, Snider LM, Majnemer A, Mazer B. Predictive validity of Prechtl's method on the qualitative assessment of general movements: a systematic review of the evidence. Dev Med Child Neurol 2011;53(10):896-906.

75. Yang H, Einspieler C, Shi W, Marschik PB, Wang Y, Cao Y, LiH, Liao YG, Shao XM. Cerebral palsy in children: movements and postures during early infancy, dependent on preterm vs. full term birth. Early Hum Dev 2012;88(10): 837-843.

76. Skiöld B, Eriksson C, Eliasson AC, Adén U, Vollmer B. General movements and magnetic resonance imaging in the prediction of neuromotor outcome in children born extremely preterm. Early Hum Dev 2013;89(7):467-472.

77. Nieuwenhuis T, da Costa SP, Bilderbeek E, Geven WB, van der Schans CP, Bos AF. Uncoordinated sucking patterns in preterm infants are associated with abnormal general movements. J Pediatr 2012;161(5):792-798.

78. Slattery J, Morgan A, Douglas J. Early sucking and swallowing problems as predictors of neurodevelopmental outcome in children with neonatal brain injury: a systematic review. Dev Med Child Neurol 2012;54(9):796-806.

79. Bosanquet M, Copeland L, Ware R, Boyd R. A systematic review of tests to predict cerebral palsy in young children. Dev Med Child Neurol 2013;55(5):418-426. 